\title{
Relation of left atrial peak systolic strain with left ventricular diastolic dysfunction and brain natriuretic peptide level in patients presenting with ST-elevation myocardial infarction
}

\author{
Cem Dogan ${ }^{*}$ Nihal Ozdemir, Suzan Hatipoglu, Ruken Bengi Bakal, Mehmet Onur Omaygenc, Baris Dindar, \\ Ozkan Candan, Mehmet Yunus Emiroglu and Cihangir Kaymaz
}

\begin{abstract}
Background: In patients presenting with ST-elevation myocardial infarction (STEMI), we investigated the relation of left atrial (LA) deformational parameters evaluated by two-dimensional speckle tracking imaging (2D-STI) with conventional echocardiographic diastolic dysfunction parameters and B-type natriuretic peptide (BNP) level.

Methods: Ninety STEMI patients who were treated with primary percutaneous coronary intervention (PCI) and 22 healthy control subjects were enrolled. STEMI patients had echocardiographic examination 48 hours after the PCl procedure and venous blood samples were drawn simultaneously. In addition to conventional echocardiographic parameters, LA strain curves were obtained for each patient. Average peak LA strain values during left ventricular (LV) systole (LAs-strain) were measured.

Results: BNP values were higher in MI patients compared to controls. Mean LAs-strain in control group was higher than $\mathrm{Ml}$ group ( $30.6 \pm 5.6 \%$ vs. $21.6 \pm 6.6 \% ; p=0.001)$. LAs-strain had significant correlation with LVEF $(r=0.51$, $p=0.001)$, also significant inverse correlations between LAs-strain and BNP level ( $r=-0.41, p=0.001)$, E/Em $(r=-0.30, p=0.001)$, LA maximal volume $(r=-0.41, p=0.001)$, LA minimal volume $(r=-0.50, p=0.001)$ and LV end systolic volume $(r=-0.37, p=0.001)$ were detected. The cut off value of $L A s-s t r a i n$ to predict BNP $>100 \mathrm{pg} / \mathrm{ml}$ was determined as $19.9 \%$ with $55.3 \%$ sensitivity and $77.2 \%$ specificity ( $p<0.05$ AUC:0.7).
\end{abstract}

Conclusion: Our study showed that LAs-strain values decreased consistently with deteriorating systolic and diastolic function in STEMI patients treated with primary PCI. LA-s strain measurements may be helpful as a complimentary method to evaluate diastolic function in this patient population.

Keywords: Acute myocardial infarction, Left atrial strain, Brain natriuretic peptide, Diastolic dysfunction

\section{Introduction}

Acute myocardial infarction (MI) results in left ventricular (LV) both systolic and diastolic dysfunction in survivors. During the early phases of MI $38 \%$ of patients have impaired relaxation and $24 \%$ of patients have restrictive LV filling pattern [1]. The important consequence of diastolic dysfunction is elevated filling pressures [2,3]. LV diastolic dysfunction was related to morbidity and death independently from systolic function in acute MI $[4,5]$.

\footnotetext{
* Correspondence: cemcardio@hotmail.com

Kosuyolu Heart \& Research Hospital, Cardiology Clinic, Istanbul, Kartal 34846, Turkey
}

\section{Biomed Central}

Thus, assessment of diastolic function and LV filling pressures after MI has important prognostic implications.

Diastolic function can be evaluated with several noninvasive and invasive techniques [3]. Tissue Doppler imaging (TDI) derived indices, including systolic velocity (S), early $(\mathrm{Em})$ and late $(\mathrm{Am})$ diastolic velocities of mitral annulus and early mitral inflow peak velocity (E)/Em ratio are sensitive and widely used parameters to estimate $\mathrm{LV}$ filling pressures [6]. Increased B-type natriuretic peptide (BNP) levels also provide reliable estimation of LV filling pressures, especially for left ventricular end 
diastolic pressure (LVEDP) and pulmonary capillary wedge pressure (PCWP) [7-9].

Left atrial (LA) function and morphology is affected by increased LV filling pressures. Assessment of LA strain using two dimensional speckle tracking imaging (2D- STI) is a recently introduced and accurate method for evaluating LA functions. Recent studies have shown clinical importance of LA strain in atrial fibrillation and cardiomyopathy $[10,11]$. Moreover, decreased LA peak strain during LV systole (LAs-strain) was related to increased LVEDP, previously $[12,13]$.

In the setting of ST-elevation myocardial infarction (STEMI) treated with primary percutaneous coronary intervention (PCI), we aimed to investigate the effects of diastolic dysfunction detected by echocardiography and BNP on LA deformational parameters evaluated with 2DSTI. We also measured phasic LA volumes and assessed their relation to diastolic dysfunction and LA strain.

\section{Methods}

\section{Study population}

Study population consisted of 90 (47 anterior, 43 inferior) consecutive STEMI patients who were treated with primary PCI in our institution and 22 healthy subjects (with no known history of cardiovascular disease, hypertension and diabetes mellitus) as a control group. To constitute the study population 150 consecutive STEMI patients were examined and 90 of them fulfilled the inclusion criteria for the MI group which were; single vessel disease, patients with no known history of previous cardiovascular disease, definite diagnosis of STEMI, successful treatment with primary PCI with restoration of TIMI flow grade 2 or 3 and absence of cardiogenic shock. Patients with atrial fibrillation, moderateto-severe valvular stenosis or regurgitation, as well as patients whose LA had an insufficient imaging quality, were also excluded from the study. The study was approved by the local ethical committee (Institutional Review Board: Kosuyolu Heart Center İnstutitional Board). Oral and written informed consent was obtained from the patients.

\section{Risk factors}

Arterial hypertension was defined as a reported blood pressure of $>140 / 90 \mathrm{~mm} \mathrm{Hg}$ or in patients receiving anti-hypertensive therapy. Diabetes mellitus was defined according to the World Health Organization definition as a fasting blood glucose concentration of $>126$ or $>200 \mathrm{mg} / \mathrm{dL} 2 \mathrm{~h}$ after an oral glucose tolerance test or in patients receiving permanent medical anti-diabetic

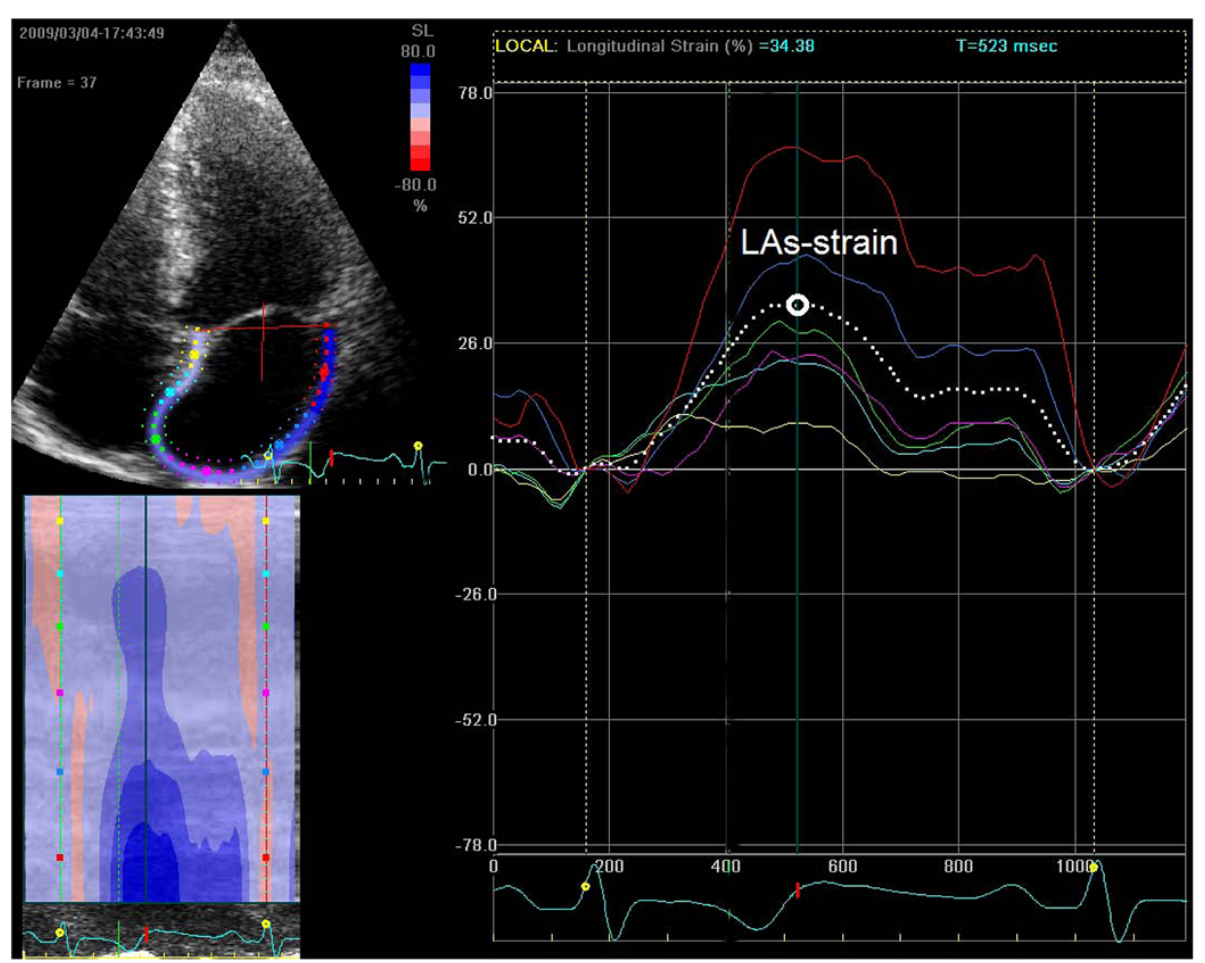

Figure 1 Measurement of LAs-strain on an image obtained from apical four-chamber view. LAs-strain, peak left atrial strain during left ventricular systole. 
Table 1 Demographic characteristics of STEMI patients

\begin{tabular}{ll}
\hline Gender, Male (\%) & 89.4 \\
Age, years (Mean \pm SD) & $52.4 \pm 8.7$ \\
Family history (\%) & 11 \\
Hypertension (\%) & 30.4 \\
Diabetes mellitus (\%) & 14.3 \\
Hyperlipidemia (\%) & 28 \\
Smoking (\%) & 72 \\
Door to balloon time, min (Mean \pm SD) & $114 \pm 15$ \\
Ml localization, anterior wall (\%) & 42.5 \\
Peak CK (mg/dl) (Mean \pm SD) & $2311.1 \pm 1612.5$ \\
Peak CK-MB (mg/dl) (Mean \pm SD) & $222.5 \pm 158.8$ \\
Peak Troponin I (ng/dl) (Mean \pm SD) & $67.7 \pm 42.8$ \\
\hline
\end{tabular}

MI myocardial infarction.

therapy. Hyperlipidemia was defined as blood total cholesterol concentrations of $>180 \mathrm{mg} / \mathrm{dL}$ or low density lipoprotein of $>130 \mathrm{mg} / \mathrm{dL}$ or when patients were receiving permanent treatment with lipid-lowering agents.

\section{Conventional echocardiography}

All patients underwent an echocardiographic examination in the left lateral position, using the GE Vivid 7 system (GE Vingmed Ultrasound AS, Horten, Norway) with a $3.5 \mathrm{MHz}$ transducer. Blood pressure and heart rate were continuously monitored during the transthoracic examination. All data were transferred to a

Table 2 Comparison of some clinical characteristics of STEMI and control patients

\begin{tabular}{llll}
\hline & MI & CONTROL & P \\
\hline Age, years & $52.4 \pm 8.7$ & $50.1 \pm 4.7$ & 0.220 \\
Sex, \% (Male) & 89 & 83 & 0.543 \\
BNP, pg/ml* & $140[12-1249]$ & $5[3-23]$ & 0.001 \\
E, m/s & $0.6 \pm 0.1$ & $0.8 \pm 0.1$ & 0.001 \\
A, m/s & $0.7 \pm 0.1$ & $0.8 \pm 0.1$ & 0.001 \\
E/A & $0.8 \pm 0.3$ & $1.4 \pm 0.3$ & 0.001 \\
Em septal, cm /s & $5.7 \pm 1.7$ & $7.2 \pm 1.5$ & 0.001 \\
Em lateral, cm/s & $6.3 \pm 1.9$ & $8.0 \pm 1.8$ & 0.001 \\
E/Em septal & $13.6 \pm 3.1$ & $11.0 \pm 1.9$ & 0.001 \\
E/Em lateral & $13.2 \pm 2.7$ & $10.8 \pm 1.4$ & 0.001 \\
LVEDV, ml & $110.1 \pm 18.4$ & $107.0 \pm 18.6$ & 0.5 \\
LVESV, ml & $59.4 \pm 15.2$ & $41.7 \pm 8.1$ & 0.005 \\
LVEF, \% & $46.6 \pm 9.2$ & $61.0 \pm 5.2$ & 0.001 \\
\hline BNP indicates brain natriuretic & &
\end{tabular}

$B N P$ indicates brain natriuretic peptide, $E$ early mitral inflow velocity, $A$ mitral inflow velocity during atrial contraction, $E m$ early mitral annular tissue Doppler diastolic velocity, LVEDV, left ventricular end diastolic volume, LVESV left ventricular end systolic volume, LVEF left ventricular ejection fraction

*Median values and range are given in the table for BNP.
Table 3 Echocardiographic assessment of left atrium

\begin{tabular}{llll}
\hline & MI & CONTROL & P \\
\hline LAV $_{\text {max }}(\mathrm{ml})$ & $47.6 \pm 12.5$ & $41.1 \pm 10.4$ & 0.001 \\
LAV $_{\text {min }}(\mathrm{ml})$ & $23.2 \pm 16.3$ & $16.3 \pm 5.6$ & 0.001 \\
LAV $_{\text {res }}(\mathrm{ml})$ & $26.1 \pm 8.7$ & $21.7 \pm 5.3$ & 0.010 \\
LA-s strain (\%) & $21.6 \pm 6.6$ & $30.6 \pm 5.6$ & 0.001 \\
LAEF (\%) & $51.7 \pm 8.3$ & $60.4 \pm 10.3$ & 0.001 \\
\hline
\end{tabular}

$L A V$ indicates left atrial volume index, $L A$ left atrium, $L A s-s$ strain peak left atrial strain during left ventricular systole, max maximal; min minimal, res reservoir.

workstation for further offline analysis (EchoPAC PC; GE). STEMI group patients had echocardiographic examination 48 hours after the PCI procedure. Transmitral early (E) and atrial contraction (A) flow velocities were obtained by pulsed-wave Doppler in the apical fourchamber view. The ratio of E/A velocity and E-wave deceleration time were measured. For TDI, the same echocardiography machine was used to acquire TDI data at high frame rates. The Nyquist limit was set at $15-20 \mathrm{~cm} / \mathrm{s}$, and minimal optimal gain was used. The myocardial systolic $(\mathrm{Sm})$, early diastolic $(\mathrm{Em})$, and late diastolic (Am) velocities were obtained at the septal and lateral mitral annulus by placing a tissue Doppler sample volume. The E/Em for septal and lateral annulus, additionally E/A ratios were subsequently calculated. LA dimensions and LV end-systolic (LVESD) and enddiastolic diameters (LVEDD) were measured. LV ejection fraction (LVEF) was estimated by Simpson's biplane method using apical 4-chamber and 2-chamber views.

The following LA volumes were measured from apical 4 and 2 chamber views by using biplane modified Simpson's method and indexed to body surface area (BSA):

Maximum LA volume $\left(\mathrm{LAV}_{\max }\right)$ : measured during $\mathrm{LV}$ contraction just before mitral valve opening

Minimum LA volume $\left(\mathrm{LAV}_{\text {min }}\right)$ : measured at the QRS onset on electrocardiography

LA reservoir volume $\left(\mathrm{LAV}_{\text {res }}\right): \mathrm{LAV}_{\text {max }}-\mathrm{LAV}_{\text {min }}$

LA ejection fraction (LAEF): $\left[\mathrm{LAV}_{\max }\right]-\left[\mathrm{LAV}_{\min }\right] /$ $\left[\mathrm{LAV}_{\max }\right]$

\section{2-D speckle tracking imaging analysis of left atrium}

Two-dimensional echocardiography images for the LA were obtained from the apical four-chamber view. All images were obtained while the patients held their breath at end expiration and the images were stored in a cineloop format from three consecutive beats. The frame rate for images was set between 60 and 90 frames/s. After defining the endocardial border manually, tracings were developed by the software system automatically for each frame. If the automatically obtained tracking segments were adequate for analysis, the software system was allowed to read the data, whereas analytically inadequate 

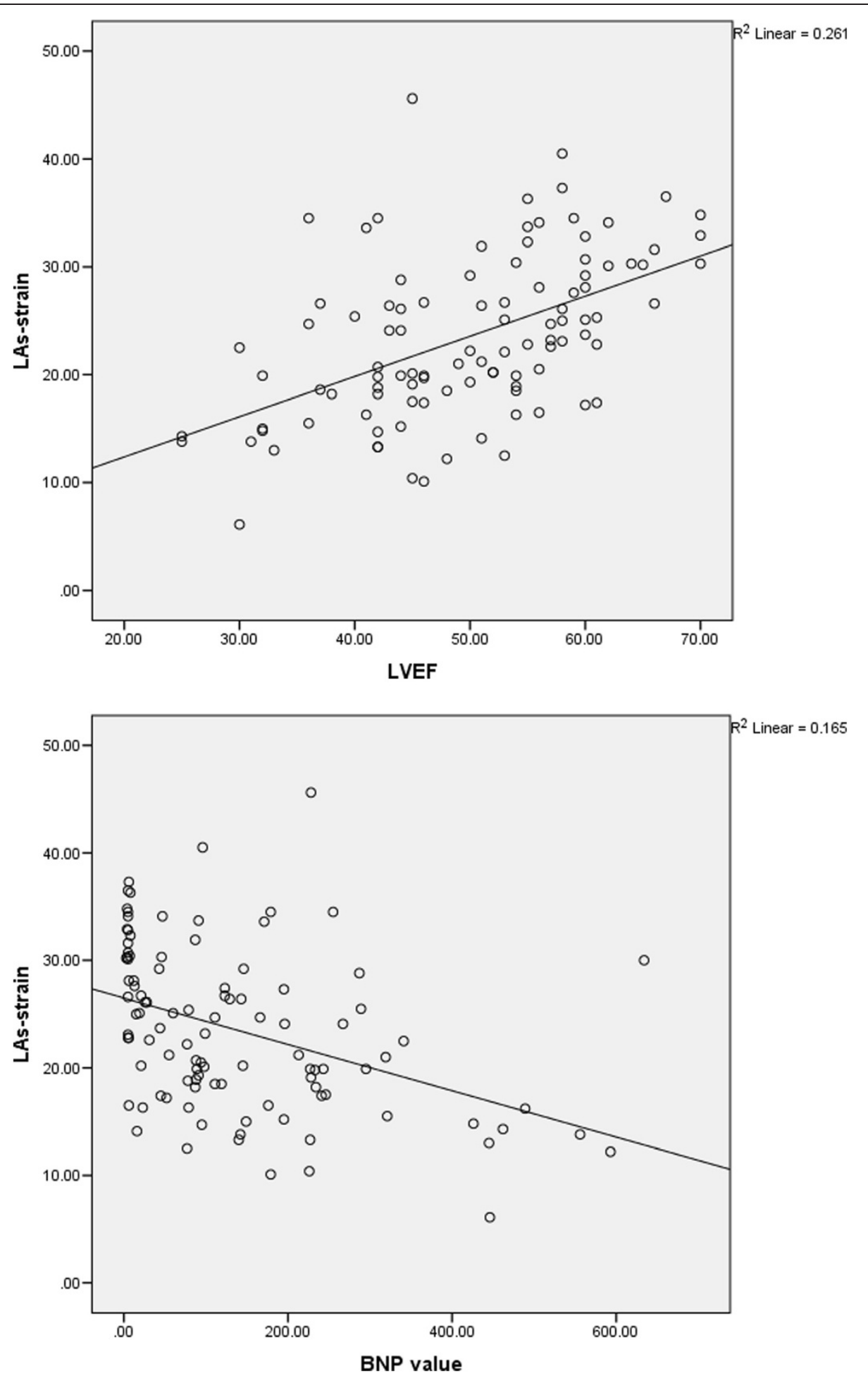

Figure 2 Correlations of peak left atrial strain during left ventricular systole with BNP level and LVEF. BNP, brain natriuretic peptide; LAs-strain, peak left atrial strain during left ventricular systole; LVEF, left ventricular ejection fraction.

tracking segments were either corrected manually or excluded from the analysis. Image tracking algorithm divided the LA wall into 6 segments automatically. The most frequently excluded segments were the ones containing pulmonary vein entrances and LA apex. The typical LA strain curves were obtained for each patient. Average peak LA strain values during LV systole (LAs-strain) for 6 segments were measured (Figure 1). 


\section{BNP measurement}

Venous blood samples were drawn simultaneously with echocardiographic examination both in STEMI patients and control subjects. The samples were immediately centrifuged at $1500 \mathrm{rpm}$ for five minutes and plasma was stored at $-80 \mathrm{C}^{\circ}$ until the time of measurement. The quantitative determination of BNP in plasma was done by immune fluorescence method using the ADVIA Centaur System (Bayer Health Care, Tarrytown, NY, ABD).

\section{Reproducibility}

Intra- and inter-observer reproducibility for the LAsstrain was assessed. For intra-observer assessment, images from randomly selected 25 patients were re-analyzed after a week. The Bland-Altman analysis and the intra-class correlation coefficient (ICC) showed good inter- and intra-observer agreement; for inter-observer agreement for LAs-strain, the mean difference was $1.8(-1.9,4.5)$ and ICC 0.87; and for intra-observer agreement, the mean difference was $1.3(-2.1,3.2)$ and ICC 0.91.

\section{Statistical analysis}

Continuous variables were expressed as mean (SD) or median (interquartile range) as appropriate. The level of significance was 0.05 . To compare parametric continuous variables, the independent Student t-test or the MannWhitney U-test was used. For categorical variables, the $\mathrm{x}^{2}$ test was used. Correlations between variables were tested by using the Pearson or Spearman's correlation tests. Receiver-operating characteristic (ROC) curves were plotted to determine the optimal cut-off values for LA strain of STEMI patients in order to predict increased BNP. Statistical analyses were performed mainly using SPSS, version 15.0 for Windows; and Medcalc software for Windows was also used when necessary.

\section{Results}

There was a male dominancy in both MI (\%89) and control (\%83) patients; the mean age of subjects were $52.4 \pm$ 8.7 years in MI group and $50.1 \pm 4.7$ years in control group. Demographic characteristics of STEMI patients are shown in Table 1, also comparison of some clinical characteristics of STEMI and control patients are presented in Table 2. Average time spent for offline analysis of LAs-strain for each patient was 4 minutes and \%94 of LA segments were tracked appropriately by the software and included in our analysis.

BNP values were significantly higher in MI patients compared to control subjects (140 [12.0-1249.5] vs. 5.0 [3.0-23.1]; pg/ml p=0.001). The differences between the measurements of transmitral flow velocities (E, A) and $\mathrm{E} / \mathrm{Em}, \mathrm{E} / \mathrm{A}$ ratios of the groups were also significant (See Table 2). Maximum and minimum left atrial volumes were increased in MI patients (Table 3). Mean LAs-strain in control group was higher than MI group (30.6 $\pm 5.6 \%$ vs. $21.6 \pm 6.6 \% \mathrm{p}=0.001$ ).

LAs-strain had significant correlation with LVEF $(\mathrm{r}=0.51, \mathrm{p}=0.001)$, also there was a significant inverse correlation between LAs-strain and BNP level $(r=-0.41$, $\mathrm{p}=0.001), \mathrm{E} / \mathrm{Em}(\mathrm{r}=-0.30, \mathrm{p}=0.001), \mathrm{LAV}_{\text {max }}(\mathrm{r}=-0.41$, $\mathrm{p}=0.001), \mathrm{LAV}_{\text {min }}(\mathrm{r}=-0.50, \mathrm{p}=0.001), \operatorname{LAEF}(\mathrm{r}=0.38$ $\mathrm{p}=0.001)$ and $\operatorname{LVESV}(\mathrm{r}=-0.37, \mathrm{p}=0.001)$ (Figure 2).

When the ROC curves were plotted for LA strain to predict increased BNP in STEMI patients; the cut off value of LA strain during LV systole was 19.9\% for the MI patients whose BNP values were higher than $100 \mathrm{pg} /$ $\mathrm{ml}$ with $55.3 \%$ sensitivity and $77.2 \%$ specificity $(\mathrm{p}<0.05$; $\mathrm{AUC}=0.7$ ) (Figure 3).

\section{Discussion}

In our study we demonstrated that LAs-strain was significantly reduced after STEMI compared to controls, additionally it was closely related with LVEF and BNP level. E/Em ratio, LA volumes and BNP were also significantly increased in STEMI patients reflecting increased diastoling filling pressures and diastolic dysfunction. Moreover, LAs-strain value of $\leq 19.9 \%$ predicted MI patients whose BNP values were higher than $100 \mathrm{pg} / \mathrm{ml}$ with $55.3 \%$ sensitivity and $77.2 \%$ specificity.

Patients who have elevated LV filling pressures after acute MI are more likely to suffer from chronic heart failure and have an increased mortality. Using the E/Em

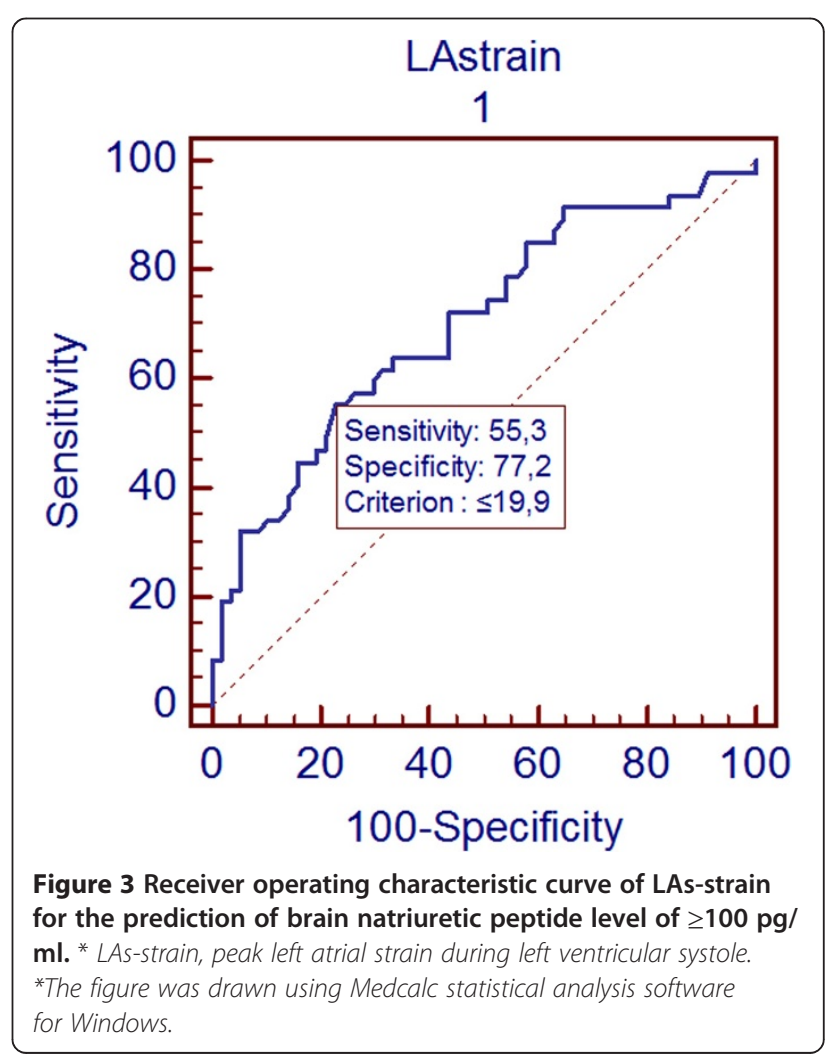


ratio, a close approximation of LV filling pressures can be obtained in a wide spectrum of patients $[14,15]$. The E/Em ratio is superior to other echocardiographic indices in this respect [16]; and after AMI, an elevated ratio predicts higher mortality and an increased risk of adverse remodeling $[17,18]$. However, an E/Em ratio between 8 and 15 , was associated with a very wide range of mean LV diastolic pressures in the study by Ommen et al. [16]. Because most of our patients had E/Em ratio between 8 and 15, further echocardiographic measurements evaluating LA volumes and function were conducted. E/Em ratios were significantly higher in our STEMI patients.

When indexed to BSA, LA volume is independently associated with increased cardiovascular risk and disease burden [19] and is a powerful predictor of medium-term outcome in patients with suspected heart failure [20], as well as in patients with acute MI $[21,22]$. We suppose that increased LA volumes measured by Simpson's method in our STEMI patients was a consequence of LA dilation as an adaptation to LV volume and pressure overload. In the setting of STEMI, initially LA enlargement contributes to improve cardiac output as an adaptive mechanism; however when optimal Frank-Starling relation is exceeded this enlargement results in decreased LA compliance and increased risk of atrial arrhythmias [23].

Two-dimensional speckle tracking imaging was shown in many studies to be useful in quantification of atrial deformation $[24,25]$. The LA deformation curves obtained with 2D-STI imaging are similar to LA volume curves. LA function and volume curves include three phases known as reservoir, conduit and booster pump [26]. LAs-strain is closely related to the LA reservoir function, besides the LA strain during atrial systole is related to the boosterpump function [12]. The LA reservoir function is assessed in two consecutive phases as early and late. While the early reservoir function depends on LA relaxation, the late reservoir function depends on LV contraction through the descent of the base during systole $[27,28]$. Therefore, both LA relaxation and LV systolic function might affect the LA reservoir function and so LA-s strain. Wakami et al. investigated the effect of LVEDP on LAs-strain during LV systole [12]. They found that elevated LVEDP is associated with a decrease of LA-s strain. Moreover, several studies demonstrated the superiority of peak systolic atrial myocardial deformation parameters to diastolic atrial deformation parameters, as a predictor of AF and cardiovascular events [29-31]. Thus, in our study we measured LA-s strain in order to assess diastolic dysfunction after STEMI.

In addition to the LAs-strain being an index of the reservoir function, it is also closely related to LV systolic function as mentioned previously [27]. Cameli et al. reported a good correlation between the peak LA strain and PCWP in patients with advanced heart failure [32]. Our findings were also compatible with these data; in our MI patients mean LAs-strain was significantly lower than controls and LA strain was correlated with LVEF. Our MI population exhibited a significant decrease in both systolic and diastolic LV function.

Biomarkers such as BNP may also be used to estimate elevated LV filling pressures [33]. Levels of BNP correlate with increased PCWP and LVEDP [9,34]. We observed that LAs-strain was negatively correlated to BNP level as well as echocardiographic parameters of diastolic function such as E/Em, LAV max, LAV min and LV end systolic volume. Additionally, when the cut off value of LA strain during LV systole was accepted to be $\leq 19.9 \%$, MI patients with BNP values $\geq 100 \mathrm{pg} / \mathrm{ml}$ were predicted with $55.3 \%$ sensitivity and $77.2 \%$ specificity.

The current study has several limitations. Strain rate and strain have been shown to be influenced by preload change and evaluation of LA function by 2D-STI is relatively difficult and time-consuming, besides; to obtain appropriate LA images for strain analysis in patients with insufficient echocardiographic images is difficult and sometimes impossible. The major limitation of our study was that instead of measuring LVEDP invasively, it was estimated using BNP and echocardiographic parameters. The patients were not followed prospectively to assess the prognostic impact of decreased LAs-strain after MI.

In conclusion, we observed that LAs-strain values decreased consistently with deteriorating systolic and diastolic function and decreased LAs-strain values also predicted $\mathrm{BNP}>100 \mathrm{pg} / \mathrm{ml}$ in STEMI patients treated with primary PCI. With this study we suggest that, LA-s strain measurements may be helpful as a complimentary method to evaluate diastolic function when inconclusive results are obtained by conventional echocardiographic parameters.

\section{Competing interests}

The authors declare that they have no conflicts of interest.

\section{Authors' contributions}

CK,NO and CD constituted the study design; CD, OC, MYE, RBB, BD and MOO performed the echocardiographic examinations and collected the patient data, SH and CD carried out statistical analysis and drafted the manuscript. All authors read and approved the manuscript.

Received: 6 March 2013 Accepted: 4 June 2013

Published: 5 July 2013

\section{References}

1. Poulsen SH, Jensen SE, Egstrup K: Longitudinal changes and prognostic implications of left ventricular diastolic function in first acute myocardial infarction. Am Heart J 1999, 137(5):910-918.

2. Litwin SE, Grossman W: Diastolic dysfunction as a cause of heart failure. J Am Coll Cardiol 1993, 4 Suppl A:49A-55A.

3. Mandinov L, Eberli FR, Seiler C, Hess OM: Diastolic heart failure. Cardiovasc Res 2000, 45(4):813-825.

4. Oh JK, Ding ZP, Gersh BJ, Bailey KR, Tajik AJ: Restrictive left ventricular diastolic filling identifies patients with heart failure after acute myocardial infarction. J Am Soc Echocardiogr 1992, 5(5):497-503.

5. Nijland F, Kamp O, Karreman AJP, van Eenige MJ, Visser CA: Prognostic implications of restrictive left ventricular filling in acute myocardial 
infarction: a serial Doppler echocardiographic study. J Am Coll Cardiol 1997, 30:1618-1624

6. Yamamoto T, Oki T, Yamada H, Tanaka H, Ishomoto T, Wakatsuki T, et al: Prognostic value of atrial sistolic mitral annular motion velocity in patients with left ventricular systolic dysfunction. J Am Soc Echocardiogr 2003, 16:333-339.

7. Bansal M, Marwick TH: Natriuretic peptides and filling pressure at rest and stress. Heart Fail Clin 2008, 4(1):71-86.

8. Parsonage WA, Galbraith AJ, Koerbin GL, Potter JM: Value of B-type natriuretic peptide for identifying significantly elevated pulmonary artery wedge pressure in patients treated for established chronic heart failure secondary to ischemic or idiopathic dilated cardiomyopathy. Am J Cardiol 2005, 95(7):883-885.

9. Maeda K, Tsutamoto T, Wada A, Hisanaga T, Kinoshita M: Plasma brain natriuretic peptide as a biochemical marker of high left ventricular enddiastolic pressure in patients with symptomatic left ventricular dysfunction. Am Heart J 1998, 135(5 Pt 1):825-832.

10. Cameli M, Lisi M, Righini FM, Focardi M, Alfieri O, Mondillo S: Left atrial speckle tracking analysis in patients with mitral insufficiency and history of paroxysmal atrial fibrillation. Int J Cardiovasc Imaging 2012, 28(7):1663-1670.

11. D'Andrea A, Caso P, Romano S, Scarafile R, Cuomo S, Salerno G, et al: Association between left atrial myocardial function and exercise capacity in patients with either idiopathic or ischemic dilated cardiomyopathy: a two-dimensional speckle strain study. Int J Cardiol 2009, 132(3):354-363.

12. Wakami K, Ohte N, Asada K, Fukuta H, Goto T, Mukai S, et al: Correlation between left ventricular end-diastolic pressure and peak left atrial wall strain during left ventricular systole. J Am Soc Echocardiogr 2009, 22(7):847-851.

13. Kurt M, Tanboga IH, Aksakal E, Kaya A, Isik T, Ekinci M, Bilen E: Relation of left ventricular end-diastolic pressure and $\mathrm{N}$-terminal pro-brain natriuretic peptide level with left atrial deformation parameters. Eur Heart J Cardiovasc Imaging 2012, 13(6):524-530.

14. Nagueh SF, Middleton KJ, Kopelen HA, Zoghbi WA, Quiñones MA: Doppler tissue imaging: a non-invasive technique for evaluation of left ventricular relaxation and estimation of filling pressures. J Am Coll Cardiol 1997, 30:1527-1533.

15. Garcia MJ, Ares MA, Asher C, Rodriguez L, Vandervoort P, Thomas JD: An index of early left ventricular filling that combined with pulsed doppler peak E velocity may estimate capillary wedge pressure. J Am Coll Cardiol 1997, 29:448-45420.

16. Ommen SR, Nishimura RA, Appleton CP, Miller FA, Oh JK, Redfield MM, et al: Clinical utility of doppler echocardiography and tissue doppler imaging in the estimation of left ventricular filling pressures. A comparative simultaneous Doppler-catheterization study. Circ 2000, 102:1788-1794.

17. Hillis GS, Møller JE, Pellikka PA, Gersh BJ, Wright RS, Ommen SR, et al: Noninvasive estimation of left ventricular filling pressure by $E / e^{\prime}$ is a powerful predictor of survival following acute myocardial infarction. J Am Coll Cardiol 2004, 43:360-3677.

18. Hillis GS, Ujino K, Mulvagh SL, Hagen ME, Oh JK: Echocardiographic indices of increased left ventricular filling pressure and left ventricular dilation after reperfused acute myocardial infarction. J Am Soc Echocardiogr 2006, 19:450-456

19. Tsang TS, Barnes ME, Gersh BJ, Bailey KR, Seward JB: Left atrial volume as a morphophysiological expression of left ventricular diastolic dysfunction and relation to cardiovascular risk burden. Am J Cardiol 2002, 90:1284-1289.

20. Lim TK, Dwivedi G, Hayat S, Majumdar S, Senior R: Independent value of left atrial volume index for the prediction of mortality in patients with suspected heart failure referred from the community. Heart 2009, 95:1172-1178

21. Møller JE, Hillis GS, Oh JK, Seward JB, Reeder GS, Wright RS, et al: Left atria volume: a powerful predictor of survival after acute myocardial infarction. Circ 2003, 107:2207-2212.

22. Beinart R, Boyko V, Schwammenthal E, Kuperstein R, Sagie A, Hod H, et al: Long-term prognostic significance of left atrial volume in acute myocardial infarction. J Am Coll Cardiol 2004, 44:327-334.

23. Pagel PS, Kehl F, Gare M, Hettrick DA, Kersten JR, Warltier DC: Mechanical function of the left atrium: new insights based on analysis of pressurevolume relations and Doppler echocardiography. Anesthesiology 2003, 98(4):975-994

24. Saraiva RM, Demirkol S, Buakhamsri A, Greenberg N, Popovic ZB, Thomas $J D$, et al: Left atrial strain measured by two-dimensional speckle tracking represents a new tool to evaluate left atrial function. J Am Soc Echocardiogr 2010, 23:172-180.

25. Vianna-Pinton R, Moreno CA, Baxter CM, Lee KS, Tsang TS, Appleton CP: Two dimensional speckle-tracking echocardiography of the left atrium: feasibility and regional contraction and relaxation differences in normal subjects. J Am Soc Echocardiogr 2009, 22:299-305.

26. Leung DY, Boyd A, Ng AA, Chi C, Thomas L: Echocardiographic evaluation of left atrial size and function: current understanding, pathophysiologic correlates, and prognostic implications. Am Heart J 2008, 156:1056-1064.

27. Barbier P, Solomon SB, Schiller NB, Glantz SA: Left atrial relaxation and left ventricular systolic function determine left atrial reservoir function. Circ 1999, 100:427-436

28. Keren G, Bier A, Sherez J, Miura D, Keefe D, LeJemtel T: Atrial contraction is an important determinant of pulmonary venous flow. J Am Coll Cardiol 1986, 7:693-5.1.

29. Thomas L, McKay T, Byth K, Marwick TH: Abnormalities of left atrial function after cardioversion: an atrial strain rate study. Heart 2007, 93:89-95.

30. Di Salvo G, Caso P, Lo Piccolo R, Fusco A, Martiniello AR, Russo MG, et al: Atrial myocardial deformation properties predict maintenance of sinus rhythm after external cardioversion of recent-onset lone atrial fibrillation: a color doppler myocardial imaging and transthoracic and transesophageal echocardiographic study. Circ 2005, 112:387-395.

31. Inaba Y, Yuda S, Kobayashi N, Hashimoto A, Uno K, Nakata T, et al: Strain rate imaging for noninvasive functional quantification of the left atrium: comparative studies in controls and patients with atrial fibrillation. J Am Soc Echocardiogr 2005, 18:729.

32. Cameli M, Lisi M, Mondillo S, Padeletti M, Ballo P, Tsioulpas C, et al: Left atrial longitudinal strain by speckle tracking echocardiography correlates well with left ventricular filling pressures in patients with heart failure. Cardiovasc Ultrasound 2010, 8:14.

33. Lemos JA, McGuire DK, Dranzner MH: B-type natriuretic peptide in cardiovascular disease. Lancet 2003, 362:316-322.

34. Haug C, Metzele A, Kochs M, Hombach V, Grünert A: Plasma brain natriuretic peptide and atrial natriuretic peptide concentrations correlate with left ventricular end-diastolic pressure. Clin Cardiol 1993, 16:553-557.

doi:10.1186/1476-7120-11-24

Cite this article as: Dogan et al:: Relation of left atrial peak systolic strain with left ventricular diastolic dysfunction and brain natriuretic peptide level in patients presenting with ST-elevation myocardial infarction. Cardiovascular Ultrasound 2013 11:24.

\section{Submit your next manuscript to BioMed Central and take full advantage of:}

- Convenient online submission

- Thorough peer review

- No space constraints or color figure charges

- Immediate publication on acceptance

- Inclusion in PubMed, CAS, Scopus and Google Scholar

- Research which is freely available for redistribution 